\title{
KAJIAN PERUBAHAN TATAGUNA LAHAN TERHADAP TINGKAT BAHAYA EROSI DI DAS DENGKENG
}

\author{
Anik Sarminingsih ${ }^{1)}$ \\ 1)Departemen TeknikLingkungan,Fakultas Teknik, Universitas Diponegoro, Jl. Prof. Soedarto, \\ $\mathrm{SH}$, Kampus Undip Tembalang, Semarang, Indonesia 50275 \\ e-mail: anikharieka@gmail.com
}

\begin{abstract}
Abstrak
Daerah Aliran Sungai (DAS) Dengkeng merupakan salah satu Sub DAS Bengawan Solo Hulu, yang sebagian besar wilayahnya berada di kabupaten Klaten Jawa Tengah.DAS Dengkeng terindikasi sebagai salah satu DAS kritis dengan potensi rawan banjir cukup besar. Salah satu penyebab banjir adalah sungai yang semakin dangkal akibat erosi dan sedimentasi.Penelitian ini dilakukan untuk mengevaluasi perubahan tataguna lahan terhadap tingkat bahaya erosi.Prediksi Erosi didasarkan pada penelitian Wischmeier dan Smith yang menyajikan Persamaan Universal Soil Loss (USLE).Jumlah sedimen yang diangkut di sungai dengan mengalikan tingkat erosi dengan rasio pengiriman sedimen (SDR).Potensi erosi dan sedimentasi mengacu pada penggunaan lahan yang berbeda, yaitu 1990, 2000 dan 2011. Secara umum di DAS Dengkeng telah terjadi peningkatan rata-rata tingkat erosi dari 70.60 ton / ha / tahun pada tahun 1999 menjadi 76.82 ton / ha / tahun. 2011 atau jika diklasifikasikan berdasarkan tingkat bahaya erosi dengan solum tanah dangkal, maka TBE tergolongsedang menuju ke berat.Peningkatan laju erosi tidak terlampu signifikan karena mayoritas penggunaan lahan adalah sawah.TBE yang tergolong berat berada pada wilayah lahan kering dengan kelerengan curam.
\end{abstract}

Kata kunci: tataguna lahan; erosi; sedimentasi

\begin{abstract}
Dengkeng Watershed is one of the Upper Bengawan Solo Watersheds, most of the area which are in the Klaten district of Central Java. The Dengkeng watershed is indicated as one of the critical watersheds with significant flood potential. One of the causes of flooding is the river which is increasingly shallow due to erosion and sedimentation. This study was conducted to evaluate changes in land use to the level of erosion hazard. Erosion Prediction is based on Wischmeier and Smith's research which presents the Universal Soil Loss Equation(USLE). The amount of sediment transported in the river by multiplying the rate of erosion with the sediment delivery ratio $(S D R)$. The potential for erosion and sedimentation refers to different land uses, namely 1990, 2000 and 2011. In general, in the Dengkeng watershed there has been an increase in the average erosion rate from 70.60 tons/ha/year in 1999 to 76.82 tons/ ha/year in 2011 or if it is classified based on the erosion hazard level with shallow soil solum, the TBE is classified as very light to heavy. Increasing the rate of erosion is not significant because the majority of land use is rice fields. TBE which is classified as heavy is in dry land with steep slopes
\end{abstract}

Keywords: landuse; erosion; sedimentation

\section{Pendahuluan}

Bahaya erosi yang telah menurunkan produktivitas tanah merupakan masalah utama dari tahun ke tahun tetap harus dihadapi oleh pemerintah. Bahaya erosi yang menimpa lahan-lahan pertanian serta penduduk sering terjadi pada lahan-lahan yang memiliki kelerengan sekitar $15 \%$ atau lebih. Bahaya ini disebabkan selain oleh

158 Jurnal Presipitasi : Media Komunikasi dan Pengembangan Teknik Lingkungan, Vol.15 No.2 September 2018 
perbuatan manusia yang mementingkan pemuasan kebutuhan diri sendiri, juga dikarenakan pengelolaan tanah dan pengairannya yang keliru (Asdak, 2002).

Berdasarkan identifikasi potensi lahan erosi, disimpulkan bahwa lahan pertanian kering, permukiman dan kawasan wisata adalah kontributor terbesar terhadap potensi erosi (Sinaga, 2011). Identifikasi lainnya menunjukkan bahwa lahan konstruksi dan lahan pertanian memiliki konsentrasi sedimen tertinggi, sedangkan hutan dan padang rumput memiliki konsentrasi sedimen terendah (Mcintyre et al, 2015). Dinamika penggunaan lahan memiliki pengaruh terhadap kondisi hidrologi di DAS menunjukkan bahwa bahwa hasil prediksi erosi, limpasan permukaan, koefisien aliran permukaan dan koefisien regim sungai secara bersamaan meningkat dari tahun ke tahun (Sinukaban, 2011).

DAS Dengkeng sebagian besar wilayahnya berada di kabupaten Klaten, berhulu si lereng gunung Merapi di Kabupaten Boyolali mempunyai luas DAS sekitar $828,70 \mathrm{~km}^{2}$ memiliki panjang sungai utama sekitar $50 \mathrm{~km}$. Pengelolaannya berada dalam wilayah kerja Balai Besar Wilayah Sungai Bengawan Solo..

Salah satu masalah yang terjadi di Sungai Progo adalah pembentukan endapan sedimen di hilir sungai yang menyebabkan perubahan morfologi sungai dalam waktu yang relatif singkat. (Harsanto dkk, 2015). Gangguan kondisi hidrologi DAS disebabkan oleh peningkatan jumlah orang dan peningkatan kebutuhan lahan, yang membuat lahan yang seharusnya berfungsi sebagai zona penyangga berubah menjadi lahan hunian atau penggunaan lahan lainnya. Pengaruh perubahan penggunaan lahan yang tidak terkendali di DAS Dengkeng adalah terjadinya banjir dan masalah kekeringan sumber daya air pada sumber air menandakan kondisi DAS kritis.

\section{Metodologi}

\section{Area Studi}

Penelitian ini terletak di DAS Dengkengdengan luas daerah tangkapan air seluas $828,70 \mathrm{~km}^{2}$. Bagian hulu berada di wilayah Kabupaten Boyolali, dan bagian hilir bermuara di sungai Bengawan Solo di kawasan kabupaten Klaten, Provinsi Jawa Tengah.Panjang sungai utama ditinjau dari hilir kearah hulu sepanjang kurang lebih 50 $\mathrm{km}$.

\section{Pengumpulan Data}

Pengumpulan data meliputi data primer dan data sekunder. Data primer meilputi pengukuran debit sesaat di beberapa penampang serta pengambilan sample sedimen dasar guna menentukan gradasi sedimen dasar sungai. Data sekunder meliputi berbagai peta serta data hidroklimatologi.Secara ringkas data yang digunakan dalam penelitian ini ditunjukkan pada Tabel 1.

Tabel 1. Data Sekunder yang digunakan

\begin{tabular}{|c|c|c|}
\hline No & Data & Description \\
\hline 1 & Peta-peta & $\begin{array}{l}\text { Peta tataguna lahan } \\
\text { untuk berbagai } \\
\text { perubahan yang } \\
\text { diperoleh dari dinas } \\
\text { Ketuhatan, dengan } \\
\text { periode tahun 1990, } \\
2000,2011\end{array}$ \\
\hline 2 & Data hujan & $\begin{array}{l}\text { Data hujan dari } \\
\text { BPDAS Bengawan } \\
\text { Solo, BBWS } \\
\text { Bengawan Solo dan } \\
\text { instansi terkait lainnya } \\
\text { dengan periode yang } \\
\text { berbeda-beda }\end{array}$ \\
\hline 3 & $\begin{array}{l}\text { Debit sungai } \\
\text { pengamatan }\end{array}$ & $\begin{array}{l}\text { Tersedia Data AWLR } \\
\text { di Pos Duga Air di } \\
\text { Jarum }\end{array}$ \\
\hline 4 & $\begin{array}{l}\text { Peta Jenis } \\
\text { tanah }\end{array}$ & $\begin{array}{l}\text { Diperoleh dari BPDAS } \\
\text { dan Kehutanan }\end{array}$ \\
\hline 5 & $\begin{array}{l}\text { Sistem } \\
\text { Sungai }\end{array}$ & $\begin{array}{l}\text { Dianalisis dari peta } \\
\text { kontur, DEM }\end{array}$ \\
\hline
\end{tabular}

\section{Hasil dan Pembahasan}

\section{Analisis erosi dan sedimentasi}

Persamaan umum yang sering digunakan dalam prediksi erosi didasarkan pada penelitian Wischmeier dan Smith yang menyajikan Universal Soil Loss Equation (USLE). Dari perhitungan laju erosi tanah akan diperoleh jumlah sedimen yang diangkut di sungai dengan mengalikan tingkat erosi dengan rasio pengiriman sedimen (SDR), karena tidak semua sedimen yang tererosi akan diangkut semua ke sungai.

Persamaan Umum Kehilangan Tanah (PUKT) adalah:

$A=R \times K \times L \times S \times C P$

dengan:

$A=\underset{\text { Jumlah tanah yang hilang }}{\text { (tona/thn) }}$
$\mathrm{R}=$ Indeks erosivitas hujan 
$\mathrm{K}=$ Faktor erodibilitas tanah, yaitu angka yang menunjukan kemudahan tanah persatuan indeks erosivitas pada keadaan standart

$\mathrm{L} \quad=$ Faktor panjang lereng $(\mathrm{m})$

$\mathrm{S}=$ Faktor kemiringan lereng (\%)

$\mathrm{C}=$ Faktor tanaman,yaitu nisbah kehilangan tanah dan lahan yang ditanami suatu jenis tanaman terhadap kehHangan tanah dan lahan baku (terbuka diolah).

$\mathrm{P}=$ Faktor pengelolaan yaitu nisbah kehilangan tanah yang diberi pengelolaan tertentu terhadap kehilangan tanah dan lahan baku.

Modifikasi Persamaan Umum Kehilangan Tanah (MPUKT) menurut Pusat penelitian dan Pengembangan Pengairan:

$E=0,001 \times K \times S \times C \times R \times D$

dengan:

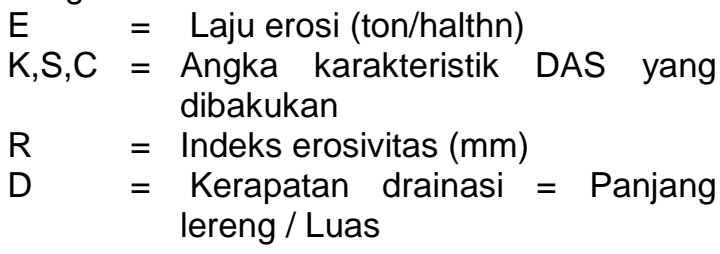

\section{Indeks Erosivitas (R)}

Perhitungan Indeks Erosivitas $(R)$ bisa digunakan persamaan Bols seperti berikut :

$\mathrm{R}=6,119(\mathrm{CH}) 1,21(\mathrm{HH})^{-0.47}(\mathrm{H} 24)^{0,53}$

Dengan :

$\mathrm{R}=$ Indeks erosivitas bulanan $(\mathrm{mm})$

$\mathrm{CH}=$ Jumlah curah hujan bulanan $(\mathrm{mm})$

$\mathrm{HH}=$ Jumlah hari hujan bulanan $(\mathrm{mm})$

$\mathrm{H} 24=$ Hujan maksimum 24 jam rerata bulanan $(\mathrm{mm})$

Dengan data curah hujan dari Stasiun Pengukur Curah Hujan Stasiun hujan di DAS Dengkeng, Indeks Erosivitas dapat dihitung. Perhitungan selengkapnya dapat dilihat pada Tabel 2 di bawah:

\section{Indeks Erodibilitas (K)}

Nilal erodibilitas tanah menggambarkan kepekaan jenis tanah terhadap erosi yang dipengaruhi oleh tenaga kinetis hujan dan limpasan permukaan air. Pada Sub DAS Dengkeng didapatkan data Indeks Erodibilitas (K) yang dapat dilihat pada Tabel 3 di bawah:

Faktor Panjang dan Kemiringan Lereng (LS)

Panjang dan kemiringan lereng merupakan sumber terjadinya terbesar dalam penerapan rumus USLE.Panjang lereng adalah batas atas lapangan hingga ketitik dimana aliran air terkonsentrasi pada saluran dilapangan, jurang atau sungai atau titik dimana mulai terjadi disposisi. Panjang dan keminingan lereng harus ditentukan dan hasil pengukuran lapangan dengan cara tiap satuan lahan dibagi menjadi satuan lahan yang lebih kecil dan dipetakan, kemudian ditentukan kemiringan lereng rata-rata (S) dalam (\%) dan panjang lereng rata-rata (L) hasil pengukuran lapangan. Selanjutnya hasil informasi tersebut dapat digunakan untuk menghitung nilai LS pada nomograf yang dimodifikasi berdasarkan rumus MC Cool SWCS (1993).

Panjang dan kemiringan lereng di lokasi penelitian dapat dilihat pada Tabel 4 .

\section{Indeks Pengelolaan Tanaman dan Konservasi Tanah (CP)}

Indeks pengelolaan tanaman (C) dapat diartikan sebagai rasio tanah yang tererosi pada suatu jenis pengelolaan tanaman pada sebidang lahan terhadap tanah yang tererosi pada lahan yang sama tanpa ada tanaman. Nilai C untuk suatu jenis pengelalaan tanaman tergantung dan jenis, kombinasi, kerapatan, panen dan rotasi tanaman. Indeks pengolahan lahan $(P)$ adalah rasio tanah yang tererosi pada suatu jenis pengelolaan lahan terhadap tanah yang tererosi pada lahan yang sama tanpa praktek pengelolaan lahan atau konservasi tanah apapun .Nilai $P$ dipengaruhi oleh campur tangan manusia terhadap lahan yang bersangkutan seperti misalnya teras, rorak, pengelolaan tanah dan sebagainya.

Tataguna lahan dalam analisisini digunakan periode 1990, 2000 dan 2011 dengan jenis penggunaan dan luas serta prosentasenya seperti pada Tabel 5 . Perubahan lahan yang terjadi pada DAS Dengkeng sesungguhnya tidak terlampau signifikan, dibandingkan DAS-DAS lain yang di dalamnya ada kota besar. Perubahan penggunaan lahan yang bersifat menurun terlihat berkurangnya kawasan hutan dan kawasan persawahan sementara yang meningkat adalah kawasan permukiman, pertanian lahan kering dan lahan terbuka.

Besaran nilai CP ditentukan berdasarkan keanekaragaman bentuk tata guna lahan dilapangan (berdasarkan peta tata guna lahan dan orientasi lapangan).Nilainya ditentukan berdasarkan hasil penelitian yang telah ada atau modifikasinya. Sebagai standar penentuan faktor $C$ dan $P$ berikut disajikan beberapa besaran nilai faktor $C$ dan $\mathrm{P}$, maupun CP yang didasarkan tataguna lahan dengan periode 1990, 2000 dan 2011 seperti pada Tabel 6. 
Tabel 2. Hasil Perhitungan Nilai Indeks Erosivitas (R)

\begin{tabular}{|c|c|c|c|c|c|c|c|c|c|c|c|c|}
\hline & Jan & Peb & Maret & Apr & Mei & Jun & Jul & Agustus & Sep & Okt & Nop & Des \\
\hline Pm & 37.93 & 31.79 & 35.34 & 25.12 & 13.80 & 5.12 & 2.43 & 1.51 & 3.51 & 8.27 & 24.30 & 34.98 \\
\hline $\mathbf{N}$ & 15.71 & 15.25 & 15.52 & 10.96 & 6.96 & 2.16 & 1.82 & 0.71 & 1.40 & 4.13 & 9.98 & 13.90 \\
\hline Pmax & 5.98 & 6.22 & 6.87 & 6.00 & 4.56 & 2.32 & 0.99 & 0.46 & 0.63 & 2.40 & 6.41 & 6.39 \\
\hline $\mathbf{R}$ & 352.12 & 294.37 & 349.87 & 253.72 & 131.65 & 48.01 & 13.44 & 7.81 & 18.63 & 64.51 & 263.97 & 350.55 \\
\hline
\end{tabular}

Tabel 3 Nilai Indeks erodibilitas (K)

\begin{tabular}{clllcc}
\hline No & \multicolumn{1}{c}{ Tanah } & \multicolumn{1}{c}{ Bahan induk } & Fisiografi & $\begin{array}{c}\text { Nilai } \\
\text { K }\end{array}$ & $\begin{array}{c}\text { Luas } \\
\text { (Ha) }\end{array}$ \\
\hline 1 & $\begin{array}{l}\text { Aluvial Kelabu dan } \\
\text { Aluvial Coklat }\end{array}$ & Endapan liat dan pasir & Dataran & 0.193 & 5153 \\
& $\begin{array}{l}\text { Kekelabuan } \\
\text { Grumusol Kelabu }\end{array}$ & Endapan Liat & Dataran & 0.157 & 9240 \\
3 & $\begin{array}{l}\text { Kompleks Regosol } \\
\text { Kelabu dan Grumusol } \\
\text { Kelabu Tua }\end{array}$ & Batukapur dan napal & $\begin{array}{l}\text { Bukit } \\
\text { lipatan }\end{array}$ & 0.331 & 2188 \\
4 & $\begin{array}{l}\text { Litosol } \\
\text { Campuran batuan } \\
\text { endapan tuf - dan batuan } \\
\text { volkan }\end{array}$ & $\begin{array}{l}\text { Bukit } \\
\text { Lipatan }\end{array}$ & 0.275 & 10704 \\
& $\begin{array}{l}\text { Regosol Coklat } \\
\text { Kekelabuan } \\
\text { Regosol Kelabu }\end{array}$ & $\begin{array}{l}\text { Intermedier-Basis } \\
\text { Abu/pasir volkan } \\
\text { intermedier }\end{array}$ & Volkan & 0.172 & 17762 \\
\hline & & Volkan & 0.215 & 37822 \\
\hline
\end{tabular}

Tabel 4 Panjang dan Kemiringan Lereng

\begin{tabular}{ccc}
\hline No & $\begin{array}{c}\text { Kemiringaan } \\
\text { Lereng }\end{array}$ & $\begin{array}{c}\text { Nilai } \\
\text { LS }\end{array}$ \\
\hline 1 & $0-8 \%$ & 0.4 \\
2 & $8-15 \%$ & 1.4 \\
3 & $15-25 \%$ & 3.1 \\
4 & $25-40 \%$ & 6.8 \\
5 & $>40 \%$ & 9.5 \\
\hline
\end{tabular}

\section{Tingkat Bahaya Erosi (TBE)}

Tingkat bahaya erosi merupakan tingkat ancaman kerusakan yang diakibatkan oleh erosi pada suatu lahan. Erosi tanah dapat berubah menjadi bencana apabila laju erosi lebih cepat daripada laju pembentukan tanah. Mengetahui besarnya erosi yang terjadi di suatu wilayah merupakan hal yang penting karena selain dapat mengetahui banyaknya tanah yang terangkut juga dapat digunakan sebagai salah satu jalan untuk mencari sebuah solusi dari permasalahan tersebut. Tingkat Bahaya Erosi (TBE) dapat dihitung dengan cara membandingkan tingkat erosi di suatu lahan dengan laju erosi yang diperbolehkan pada lahan tersebut

Klasifikasi tingkat Bahaya Erosi (TBE) didasarkan pada kedalaman lapisan atas tanah (Solum).Semakin dalam lapisan atas tanah maka potensi erosi semakin kecil.Secara umum klasifikasi Tingkat Bahaya Erosi ditunjukkan pada Tabel 7. 
Tabel 5. Penggunaan Lahan di DAS Dengkeng

\begin{tabular}{|c|c|c|c|c|c|c|c|}
\hline \multirow{2}{*}{ NO } & \multirow{2}{*}{ PENGGUNAAN LAHAN } & \multicolumn{3}{|c|}{ LUAS (HA) } & \multicolumn{3}{|c|}{ LUAS (\%) } \\
\hline & & 1990 & 2000 & 2011 & 1990 & 2000 & 2011 \\
\hline 1 & Hutan lahan kering sekunder & 751 & 675 & 570 & $0.9 \%$ & $0.8 \%$ & $0.7 \%$ \\
\hline 2 & Hutan tanaman & 14130 & 14086 & 14094 & $17.1 \%$ & $17.0 \%$ & $17.0 \%$ \\
\hline 3 & Lahan terbuka & 130 & 132 & 132 & $0.2 \%$ & $0.2 \%$ & $0.2 \%$ \\
\hline 4 & Pemukiman & 20859 & 21064 & 21092 & $25.2 \%$ & $25.4 \%$ & $25.5 \%$ \\
\hline 5 & Pertanian lahan kering & 3712 & 4182 & 4025 & $4.5 \%$ & $5.0 \%$ & $4.9 \%$ \\
\hline 6 & Pertanian lahan kering campur & 7732 & 7732 & 7719 & $9.3 \%$ & $9.3 \%$ & $9.3 \%$ \\
\hline 7 & Sawah & 35411 & 34791 & 35056 & $42.7 \%$ & $42.0 \%$ & $42.3 \%$ \\
\hline 8 & Semak belukar & 2 & 66 & 39 & $0.0 \%$ & $0.1 \%$ & $0.0 \%$ \\
\hline \multirow[t]{2}{*}{9} & Tubuh air & 143 & 143 & 143 & $0.2 \%$ & $0.2 \%$ & $0.2 \%$ \\
\hline & TOTAL & 82870 & 82870 & 82870 & $100.0 \%$ & $100.0 \%$ & $100.0 \%$ \\
\hline
\end{tabular}
lahan

\begin{tabular}{rlr}
\hline $\begin{array}{c}\text { N } \\
\mathbf{O}\end{array}$ & Penggunaan Lahan & Nilai_CP \\
\hline 1 & Hutan lahan kering & 0.050 \\
2 & sekunder & Semak belukar \\
3 & Pemukiman & 0.010 \\
4 & Sawah & 0.500 \\
5 & Lahan terbuka & 0.020 \\
6 & Perkebunan & 1.000 \\
7 & Tubuh Air & 0.020 \\
8 & Pertanian lahan kering & 0.000 \\
9 & Pertanian lahan kering & 0.430 \\
10 & Hutan tanaman & 0.140 \\
& & 0.200
\end{tabular}

Berdasarkan faktor-faktor penentu erosi lahan seperti diuraikan sebelumnya berikut disajikan hasil analisis potensi erosi seperti Tabel 8. Mengacu pada kriteria tingkat bahaya erosi (TBE) yang ada maka secara umum erosi yang terjadi di wilayah DAS.

Dengkeng mempunyai kategori sangat ringan hingga berat, namun secara umum berkategori sedang. Peta spasial tingkat

\begin{tabular}{llllll} 
Table 7. Kelas Tingkat Bahaya Erosi \\
\hline $\begin{array}{lllll}\text { Solum } \\
\text { of Soil } \\
\text { (cm) }\end{array}$ & \multicolumn{5}{c}{ Tingkat Erosi } \\
\cline { 2 - 6 } & I & \multicolumn{5}{c}{ II } & IV & V \\
\cline { 2 - 6 } & \multicolumn{5}{c}{ Erosi (ton/ha/tahun) } \\
\cline { 2 - 6 } & & $15-$ & $60-$ & $180-$ & $>480$ \\
\hline Dalam & SR & R & S & B & SB \\
$>90$ & 0 & I & II & III & IV \\
\hline Sedang & S & B & SB & SB & SB \\
$60-90$ & II & III & IV & IV & IV \\
\hline Dangkal & S & B & SB & SB & SB \\
$30-60$ & II & III & IV & IV & IV \\
\hline $\begin{array}{l}\text { Sangat } \\
\text { dangkal }\end{array}$ & B & SB & SB & SB & SB \\
$<30$ & III & IV & IV & IV & IV \\
\hline
\end{tabular}

Catatan:

O-SR = Sangat Ringan; $\mathrm{I}-\mathrm{R}=$ Ringan

II-S = Sedang; III-B = Berat;

IV-B= Sangat Berat

Tabel 8. Prediksi Potensi Erosi di DAS

Dengkeng

\begin{tabular}{cccc}
\hline No Tahun & Luas & Laju Erosi & Erosi Total \\
SubDAS & Rerata \\
(Ha) & $($ Ton/Ha/Th) & $\begin{array}{c}\text { (Juta } \\
\text { Ton/Th) }\end{array}$ \\
\hline
\end{tabular}




\begin{tabular}{lllll}
\hline 01 & 1990 & $82,870.13$ & 70.60 & 5.85 \\
02 & 2000 & $82,870.13$ & 72.87 & 6.04 \\
03 & 2011 & $82,870.13$ & 76.82 & 6.37 \\
\hline
\end{tabular}

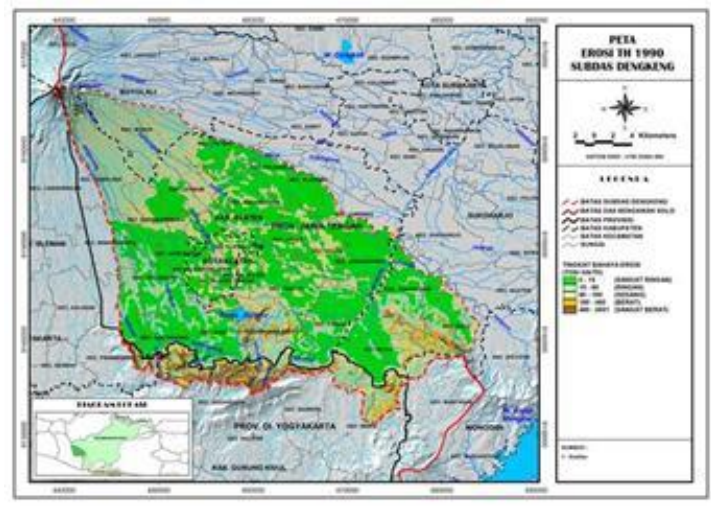

Gambar 1. Erosi DAS Dengkeng untuk Tataguna Lahan Tahun 1990

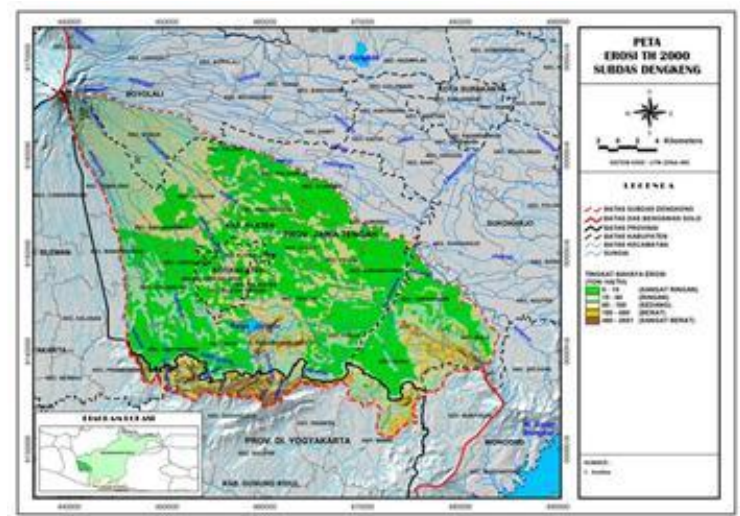

Gambar 2. Erosi DAS Dengkeng untuk Tataguna Lahan Tahun 2000

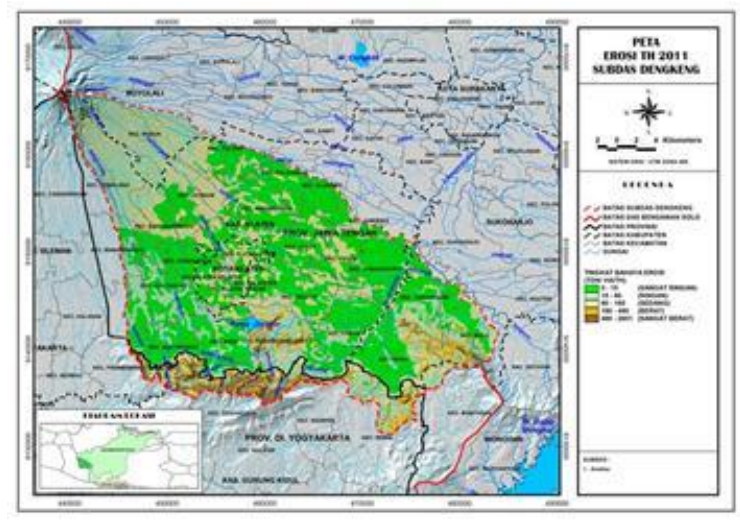

Gambar 3. Erosi DAS Dengkeng untuk Tataguna Lahan Tahun 2011

\section{Kesimpulan}

Dari perhitungan potensi erosi yang mengacu pada penggunaan lahan yang berbeda, yaitu 1990, 2000 dan 2011, secara umum di DAS Dengkeng telah terjadi peningkatan laju erosi rata-rata dari 70.60ton / ha / tahun pada tahun 1990 menjadi 76.82 ton / ha / tahun 2011. Berdasarkan kedalaman solume di DAS Dengkeng yang tergolong dangkal hingga dalam, maka kalisikasi bahaya erosi tergolong sangat ringan hingga berat.Namun secara umum tergolong tingkat bahaya erosi sedang.

Perubahan yang tidak terlampau signifikan juga ditunjukkan adanya perubahan laju erosi dan tingkat bahaya erosi yang juga tidak berubah terlalu signifikan

\section{Daftar Pustaka}

Asdak C. 2002. Hidrologi dan Pengelolaan Daerah Aliran Sungai. Yogyakarta Gadjah Mada University Press

Bambang Triatmodjo, 2008, Hidrologi Terapan, Beta offset, Yogyakarta.

Chow, V,T, Maidment, D,R, and Mays, L,W, (1988), Applied Hydrology, Mc Graw-Hill, Singapore.

I Made Kamiana, 2010, Teknik Perhitungan Debit Rencana Bangunan Air, Graha Ilmu, Yogyakarta.

J. Sinaga et al., "Analisis Potensi Erosi pada Penggunaan Lahan Daerah Aliran Sungai Sedau di Kecamatan Singkawang Selatan," vol. 2010, pp. 110, 2011.

J. Sutrisno, B. Sanim, and S. Asep, "Arahan kebijakan pengendalian erosi dan sedimentasi di sub daerah aliran sungai keduang kabupaten wonogiri (," vol. 8, no. 2, pp. 105-118, 2011.

L. O. Alwi, N. Sinukaban, S. Solahuddin, and H. Pawitan, "( STUDY OF LAND USE DYNAMIC IMPACTS TO LAND EROSION AND HYDROLOGY CONDITIONS IN WANGGU WATERSHE DS )," vol. 2, pp. 74-86, 2011.

Mutreja, K,N, (1986), Applied Hydrology, Tata Mc Graw-Hill, New Delhi,

N. D. Febrianingruma, A. Masrevaniah, and E. Suhartanto, "Pengaruh perubahan penggunaan lahan terhadap sedimen di sungai lesti," Tek.Pengair.Univ. Brawijaya, 2005.

P. Harsanto et al., "KARAKTERISTIK BENCANA SEDIMEN PADA SUNGAI VULKANIK," pp. 200-207, 2015. 
Ponce, V, M, 1989, Engineering Hidrology Principles and Practice, Prentice Hall, New Jersey.

S. C. Mcintyre and E. Reno, "Land-Use Effects on Erosion, Sediment Yields, and Reservoir Sedimentation: A Case Study in the Lago Loíza .... LAND-USE
EFFECTS ON EROSION, SEDIMENT YIELDS, THE LAGO LOÍZA BASIN , PUERTO RICO," no. November, 2015.

Suripin.2004. Sistem Drainase Yang Berkelanjutan. Penerbit Andi Offset,Yogyakarta 